\title{
Giant mediastinal mature teratoma with increased exocrine pancreatic activity presenting in a young woman: a case report
}

\author{
Franco Stella and Fabio Davoli*
}

\begin{abstract}
Introduction: Mediastinal mature teratoma is a benign, slow-growing tumor typically affecting 20- to 40-year-old adults. Fluid examination from the cystic masses rarely shows enzymatic activity as we describe in this report.

Case presentation: We report a case of a giant mediastinal germ cell tumor (measuring $15 \mathrm{~cm} \times 14 \mathrm{~cm} \times 8 \mathrm{~cm}$ ) detected in a 35-year-old Caucasian woman. Microscopic examination showed that the lesion resembled a mature cystic teratoma with areas of pancreatic tissue with mature ductal and acinar structures intermixed with islets of Langerhans. Fluid from the cysts in the mass was examined after removal showed amylase activity of $599 \mathrm{U} / \mathrm{l}$ despite normal serum levels. The post-operative period was free of complications, and the patient was discharged on post-operative day 10.
\end{abstract}

Conclusion: Complete surgical removal is the treatment of choice for mature cystic teratomas, with optimal results and acceptable surgical risk. Exocrine pancreatic function may be an aid to pre-operative or intra-operative diagnosis; however, these findings have no impact on survival or the therapeutic pathway.

\section{Introduction}

Primary germ cell tumors (GCTs) of the mediastinum are rare tumors ( $10 \%$ to $15 \%$ of all mediastinal tumors), and they usually appear during the third to fourth decade of life [1]. GCTs are predominantly found in gonads, and the anterior mediastinum is the common extragonadal site [2]. The majority of mediastinal teratomas are mature teratomas that are histologically welldefined and benign [3]. Malignant GCTs account for less than $1 \%$ of all mediastinal tumors, and mature teratomas account for approximately $8 \%$ [1].

\section{Case report}

We present a case of a giant mature teratoma of the anterior mediastinum in a 35-year-old Caucasian woman. Following the onset of an episode of influenza associated with productive cough, the patient, an exsmoker, underwent a chest X-ray which revealed the presence of a severe increase of the frontal cardiac area, with particular involvement of the atrial sectors and

\footnotetext{
* Correspondence: fab_78_16l@hotmail.com
Department of Thoracic Surgery, "S. Orsola-Malpighi" Hospital, University of

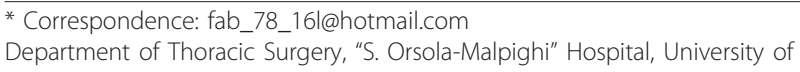
Bologna, Bologna, Italy
}

(c) 2011 Stella and Davoli; licensee BioMed Central Ltd. This is an Open Access article distributed under the terms of the Creative Commons Attribution License (http://creativecommons.org/licenses/by/2.0), which permits unrestricted use, distribution, and reproduction in any medium, provided the original work is properly cited.

evident divarication of the sternal angle. Subsequent transthoracic echocardiography showed a rounded parenchyematous extra-cardial formation measuring approximately $9 \mathrm{~cm}$ in diameter and pressing against the lower posterior wall of the right atrium, with the chambers and valves of the heart being within the norm (Ejection Fraction $=71 \%$ ), and an anomalous movement of the inter-ventricular septum. A thoracic computed tomographic scan with contrast medium confirmed the presence of a voluminous expansive formation with a maximum diameter of $125 \mathrm{~mm}$, liquid contents, clear contours, multiple compartments, and parietal calcifications. This tumor was causing compression of the adjacent pulmonary parenchyma, the vascular and bronchial structures of the right lung (subsequently confirmed with fibrobronchoscopy), and the superior vena cava, without signs of infiltration (Figure 1). The tumor markers tested while the patient was hospitalized ( $\alpha$-fetoprotein, $\beta$-HCG, and CA 19-9) were within normal ranges. Her respiratory function tests showed a prevalent, obstructive type, slight ventilatory incapacity: forced expiratory volume in one second was 2.63 (73\% of the former value), forced vital capacity was 3.63 (87\% 


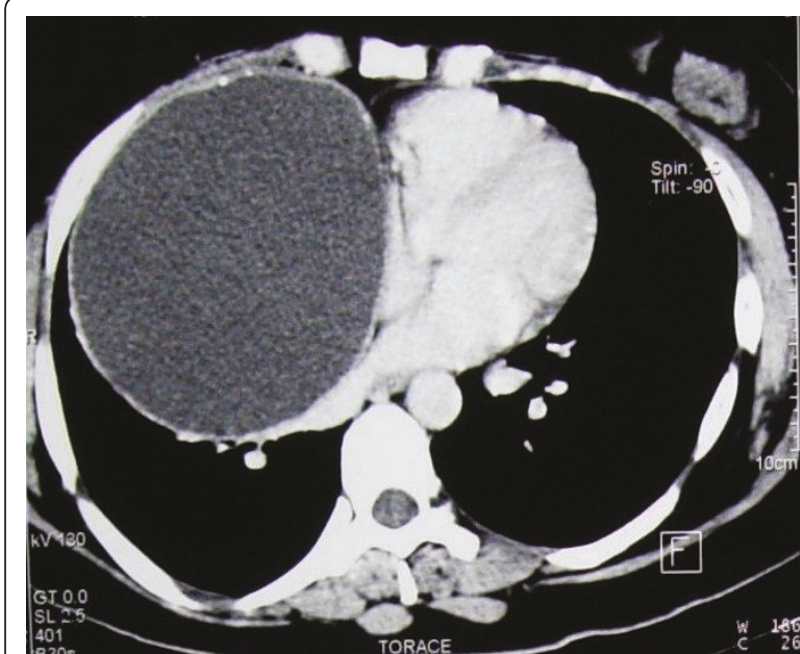

Figure 1 Chest computed tomographic scan revealing the mass compressing the mediastinal vessels.

of the former value), and blood gases at baseline and after stress were within the normal range. The day after the patient was admitted to our hospital, she underwent surgery to excise the mediastinal mass with a median sternotomy approach.

Once the mediastinal cavity was opened, it was possible to see the presence of the voluminous tumor, which occupied most of the right hemithorax with compression of the adjacent pulmonary parenchyma. There were also widespread adhesions to the superior vena cava, the ascending aorta, the pericardium, and part of the lower pulmonary lobe, where an atypical resection of pulmonary parenchyma was performed.

The lesion measured $15 \mathrm{~cm} \times 14 \mathrm{~cm} \times 8 \mathrm{~cm}$ and showed smooth, regular external contours. The cut surface of the mass was cystic, filled with a yellowish white proteinaceous material admixed with hair. A thickened area of the cyst wall measuring $6.5 \mathrm{~cm}$ across was composed of a more solid white fibrous tissue, which also contained multiple small cysts filled with yellowish material. Fluid from the cysts in the mass was examined after removal, showing an amylase activity of $599 \mathrm{U} / \mathrm{l}$ despite serum levels being normal.

Microscopically, the lesion resembled a mature cystic teratoma, which is more commonly seen in the ovary. The cystic wall was predominantly lined by a squamous epithelium associated with sebaceous glands, hair follicles, and a chronic inflammatory reaction (Figure 2). Other areas of the cyst showed a monostratified ciliated epithelium, cartilage, and mucinous glands recapitulating respiratory tract structures. More solid areas of the mass revealed pancreatic tissue with mature ductal and acinar structures intermixed with islets of Langerhans. In addition, in adipose tissue at the periphery of the

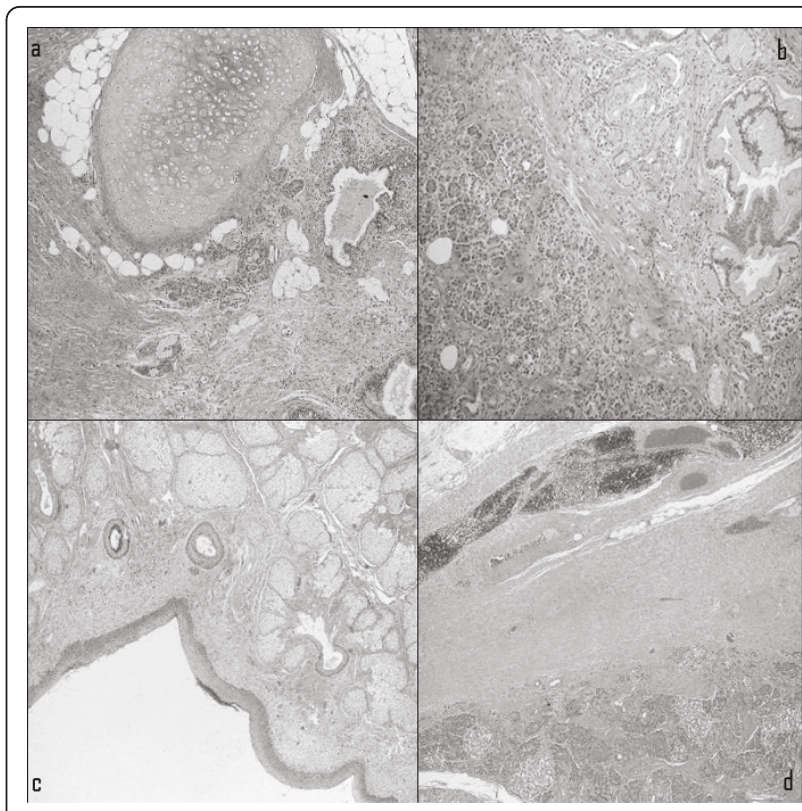

Figure 2 Microscopic histopathological examination showing various tissue components of the mature cystic teratoma of the mediastinum. (a) Cartilaginous and adipose tissue admixed with smooth muscle fibers and lined by squamous and respiratory epithelium. (b) Pancreatic tissue. (c) Skin appendages. (d) Periphery of the lesion surrounded by residual thymic tissue with rare Hassall's corpuscles.

mass, a thymic residue with prominent Hassall's corpuscles was identified. Careful examination of the mass did not reveal the presence of immature tissue. The postoperative period was uneventful, and the patient was discharged on post-operative day 10.

\section{Conclusion}

Mature teratomas typically occur in young patients (mean age, 27 years), with approximately equal frequency in men and women (> 90\% of malignant germ cell tumors occur in men). Histologic examination of mature teratomas reveals malignant transformation in less than $1 \%$ of cases and is usually characterized by the malignant degeneration of the squamous epithelium [1]. Although the actual mechanism of development is unclear, it is believed that these lesions consist of primordial germ cells which stray into midline extragonadal areas in the migration during embryonic development [4]. Most patients with germ cell tumors in the mediastinum are asymptomatic, so these neoplasms are usually discovered by accident during routine chest $\mathrm{X}$-ray examinations [3]. Patients may present with chest, back, or shoulder pain; dyspnea; fever; pleural effusion; cough; and bulging of the chest wall. Less commonly, tumors become infected or may rupture into adjacent organs, such as the lung, bronchial tree, or pleural and 
pericardial space $[2,5]$. Symptoms can also derive from the pressure exerted on the surrounding tissue (vena cava syndrome), and occasionally fluid examination from the cystic mass shows physiological activity. Some authors [6,7] have suggested that exocrine secretion by pancreatic tissue and leakage of digestive enzymes from intestinal or salivary tissue are due to non-infective inflammation around the mass. Others [8] believe that exocrine pancreatic function may be an aid to preoperative or intra-operative diagnosis. Anyway, these findings have not had an impact on survival or on the therapeutic pathway. For cases of pure mature cystic teratomas, complete surgical removal alone is the treatment of choice, with optimal results and acceptable operative risk.

\section{Consent}

Written informed consent was obtained from the patient for publication of this case report and any accompanying images. A copy of the written consent is available for review by the Editor-in-Chief of this journal.

\section{Authors' contributions}

FS chose the surgical strategy (median sternotomy) and played the greatest role during the surgical operation.

FD was a major contributor to the writing of the manuscript and to collecting all the data about the patient that suggested the particularly high levels of amylase in the cystic fluid; he also reviewed the literature. All authors read and approved the final manuscript.

\section{Competing interests}

The authors declare that they have no competing interests.

Received: 8 February 2010 Accepted: 27 June 2011

Published: 27 June 2011

\section{References}

1. Dulmet EM, Macchiarini P, SuC B, Verley JM: Germ cell tumors of mediastinum: a 30 year experience. Cancer 1993, 72:1894-1901.

2. Zisis C, Rontogianni D, Stratakos G, Voutetakis K, Skevis K, Argiriou M, Bellenis I: Teratoma occupying the left hemithorax. World J Surg Oncol 2005, 3:76.

3. Duwe BV, Sterman DH, Musani Al: Tumors of the mediastinum. Chest 2005, 128:2893-2909.

4. Karas SM, Parissis JT, Antoniades C, Loulias A: A rare case of large mediastinal germ cell tumor detected by echocardiography. Int $J$ Cardiol 2005, 101:159-161.

5. Matsubara K, Aoki M, Okumura N, Menju T, Nigami H, Harigaya H, Baba K: Spontaneous rupture of mediastinal cystic teratoma into the pleural cavity: report of two cases and review of the literature. Pediatric Hematol Oncol 2001, 18:221-227.

6. Southgate J, Slade PR: Teratodermoid cyst of the mediastinum with pancreatic enzyme secretion. Thorax 1982, 37:476-477.

7. Sommerlad BC, Cleland WP, Yong NK: Physiological activity in mediastinal teratomata. Thorax 1975, 30:510-515.

8. Kallis $\mathrm{P}$, Treasure T, Holmes SJ, Griffiths M: Exocrine pancreatic function in mediastinal teratomata: an aid to preoperative diagnosis? Ann Thorac Surg 1992, 54:741-743.

doi:10.1186/1752-1947-5-238

Cite this article as: Stella and Davoli: Giant mediastinal mature teratoma with increased exocrine pancreatic activity presenting in a young woman: a case report. Journal of Medical Case Reports 2011 5:238.

\section{Submit your next manuscript to BioMed Central and take full advantage of:}

- Convenient online submission

- Thorough peer review

- No space constraints or color figure charges

- Immediate publication on acceptance

- Inclusion in PubMed, CAS, Scopus and Google Scholar

- Research which is freely available for redistribution
C Biomed Central 